\title{
Foreword
}

\section{Public Health Law, 2002-2003: Year of Achievement}

\author{
Julie L. Gerberding, Anthony D. Moulton, \\ Richard A. Goodman, and \\ Montrece McNeill Ransom
}

$\mathrm{T}$ he first issue of the Journal of Law, Medicine and Etbics devored to public health law and ethics was published in June 2002, concurrent with a major public health law conference convened in Atlanta, Georgia. That issue celebrated the vigorous rebirth of interest in these important subjects that had surfaced just a few years earlier. The year that followed has brought even greater visibility to public health law.

\section{Pubuc Health Law in Action}

Early in 2002, the nation's concern with potential terrorism led the Centers for Disease Control and Prevention (CDC) to articulate the goal of "public health legal preparedness" and to incorporate public health law into its new program of terrorism preparedness grants. The public health legal preparedness initiative-like the drive for comprehensive public health system preparedness-helped the U.S. mount an effective response to communicable disease threats that could not have been predicted in the summer of 2002.

Severe and acute respiratory syndrome (SARS) first appeared in the world just a few months later, and both SARS and monkeypox, another infectious disease, reached the western hemisphere and the United States by early 2003. These emerging diseases were curtailed, as of this writing, in no small part through the use of two quite different public health legal interventions: isolation and quarantine in one case and control of commerce in animal vectors in the other. ${ }^{2}$ Earlier concern over terrorists' possible use of smallpox as a weapon had revitalized legal issues related to immunization and compensation for adverse consequences.

The past year has feanured other notable applications of

Journal of Law, Medicine \& Ethics, 31 (2003): 482-484. (c) 2003 by the American Society of Law, Medicine \& Ethics. law to public health issues. A few examples make the point:

- By April 2003, most states had used a draft model act, commissioned by CDC, as a diagnostic checklist to assess their existing emergency health powers. Twenty-five states and the District of Columbia had passed legislation or resolutions incorporating provisions of that template. ${ }^{2}$

- A number of states and localities adopted laws to limit exposure to secondhand smoke and to raise tobacco taxes. On the global stage, the World Health Assembly formally adopted the Framework Convention for Tobacco Control, doubly significant as the first treaty adopted by that body on any topic. ${ }^{3}$

- Following dismissal of a state suit against paint manufacturers regarding lead-based paint, fortytwo state attorneys general signed an agreement with the U.S. paint industry requiring greater disclosure to consumers of the danger of leadbased paint removal and remediation.

- States and school boards adopted a variety of laws and policies to encourage physical activity among school children and to improve the nutritional value of the food and beverages available to students;

- In the wake of two tragic nightclub fires, Rhode Island legislated strict new fire safety and building code regulations likely to become the national standard; Massachusetts, New York, Nashville and Los Angeles called for similar revisions; and

- In July and October 2002, fecleral and state health and agricultural departments investigated 
Escherichia coli and Listeria monocytogenes contaminations of beef and poultry, leading to two of the largest food recalls ever ordered in the U.S. In response to the incidents, the USDA updated rules with stricter criteria and sampling methods to prevent future outbreaks.

\section{Pubuc Health Law as Intervention AND AS INFRASTRUCTURE}

These recent events testify to the vital role law can play as a public health intervention and, as a corollary, to the concerns such interventions raise in a democracy. Many law-based interventions, of course, involve minimal coercion and are widely accepted by society, such as drinking water safety standards, food and drug labeling, and building safety codes. In other cases, healthy debates have occurred over the balance between protection of the health of the citizenry and, on the other hand, protection of individual civil and property rights. Quarantine in the SARS epidemic is an obvious example. While law is a long-established public health tool, the argument can be made that laws should not be the presumptive intervention of first choice, precisely because of the tension with civil and property rights. Another important consideration is that law-based interventions may stimulate public resistance to sensible, science-based approaches to prevention and health promotion.

In deciding whether and how to use law as an intervention for a given public health purpose, a common sense algorithm might be a useful starting point: first, assess all potentially relevant types of interventions, including, but not limited to, those that use law; second, identify both the positive and negative implications of using a law-based intervention; third, use law only when less coercive alternatives have been exhausted; and fourth, in most cases, use law-based interventions as one element in a comprehensive approach, for example, in a comprehensive strategy to prevent teen smoking.

"Infrastructural" laws are another class; laws that establish public health agencies and endow them with basic responsibilities and powers. These include, among others, the authority to collect disease and other health data, to conduct laboratory tests, to inform the public about health matters, to propose policies to elected and appointed officials, to conduct research and evaluation, to employ and train public health professionals, to prepare for and respond to public health emergencies, and to regulate health care providers.

Important work is underway in infrastructural public health law. Notable is the work of the Turning Point Public Health Statute Modernization National Collaborative. Beginning in 2000, five states collaborated to draft a model state public health act with the kinds of cross-cutting authorities they consider important to support specific public health programs and services. The collaborative published the model, following extensive public review and comment. ${ }^{4}$

\section{Cross-Sector Partnershits and the New Pubuc Heat.th Law Association}

In the past year, the public health law initiative has brought valuable new partners to the table, focused on the job of improving legal preparedness for terrorism and other public health emergencies but simultaneously laying a foundation for cross-disciplinary partnerships in other areas of public health law.

Perhaps the most important example is the pathbreaking "Forensic Epidemiology" course. Developed by the CDC Public Health Law Program and disseminated nationally in partnership with the U.S. Department of Justice and public health practice organizations, this course is training front-line public health and law professionals across the country in joint investigation of bioterrorist events and other, related threats to the public's health and safety. The important subtext is the project's creation of a practical basis for federal, state and local law enforcement officials to partner with public health counterparts in other areas, such as prevention of domestic violence. ${ }^{5}$

Often considered only a defensive ally, lawyers demonstrated the "preventive law" role they can play in public health in the context of the multijurisdictional terrorism exercise - "TOPOFF2" - held in Illinois in May 2003. Convened by the legal counsel of the Illinois state health department, a task force of attorneys from the office of the governor, the attorney general, executive branch agencies, cities and counties, and federal agencies tested legal preparedness as part of the exercise. The findings will be used to improve legal preparedness and the task force experience itself will serve as an example for public health law partnerships nationally.

Another example of fruitful, cross-sector partnerships is the important and foresighted initiative several schools of law are taking to incorporate public health law into law school curricula. Health law is a standard part of law education, but public health law is very much an afterthought. The goals of the curriculum initiative are to increase the number of attorneys who practice public health law, with special focus on the law of terrorism and other public health emergencies, and, more broadly, for all attorneys to understand the often significant implications their practice has for the health of the public.

Public health has benefited for decades from the presence of a rich network of non-profit associations and other institutions. Public health law, however, like public health finance, has had no such forum. More than eighty public health policy makers, practitioners, and academics discussed this at the 2002 public health law conference in Atlanta, Georgia, and committed to fill the gap. 
Just one year later, their commitment led to formal creation of the new Public Health Law Association, a non-profit organization charged "to promote healthy people in healthy communities through dialogue, partnerships, education and research in public health law." The association's members - elected and appointed public health policy makers, public health practitioners and attorneys, judges, researchers, students, and others - will participate in its teleconferences and electronic discussion groups, contribute to and benefit from its publications, and take part in conferences and programs designed to meet their shared interest in public health law. ${ }^{6}$

\section{Science, Systems, and Global Scope}

In summary, important, unprecedented work is underway toward the goal of public health legal preparedness. To achieve that goal fully will require sustaining that work and its supporting partnerships on a long-term basis. Additional effort is needed on at least two fronts. One is scientific: greatly expanding the applied research devoted to public health law and, specifically, to determining the impact laws have on the public's health and on the public health system. Science should be the bedrock for those who design and implement public health laws. A priority of the CDC Public Health Law Program is to support peerreviewed research into the impact law has on public health and, through that research, to stimulate growth of a bocly of empirical knowledge about public health law. ${ }^{7}$ One invaluable service of this Journal issue is to advance understanding of the scientific and ethical bases for public health law and to contribute to maintaining their balance. We congratulate the authors whose work appears in this issue and call on foundations and federal agencies to recognize public health law as a priority for sustained support.

The second front that needs attention is qualitative. To date, the scope of the U.S. public health law initiative has been restricted largely to the conventional domain of public health; the arena in which government public health departments operate. This "core" domain was the right place for the public health law initiative to start. The reality of the world, however, is that terrorism, emerging diseases like SARS, and still other health threats transcend the boundaries of the narrowly defined public health sector. We must adopt a comprehensive "health system" perspective if we are to achieve full public health legal preparedness.

Even within the public sector, many "non-public health" agencies contribute to the health of the public. This includes, for example, law enforcement agencies, Medicaid programs, schools and universities, and agencies that oversee land use and transportation laws and policies. The private sector makes important contributions as well, especially health care plans and providers, and the laws that govern them should be included in the scope of the public health law initiative.

Finally, the public health law initiative is becoming global. A national public health law center is being established at LaTrobe University in Melbourne, Australia. Similar efforts are under consideration in Korea, led by the Yonsei University Department of Bioethics and Medical Law, and in Canada.

The potential benefits of global collaboration in public health law are as great as those of the existing global collaborations that support disease reporting, outbreak investigation, and public health laboratory resting. Leaders of the U.S. public health law initiative should join with colleagues in other countries to establish global partnerships that can enrich understanding of the role public health law, distill "best practices," design and disseminate customized training, and support on a trily worldwide basis the professional interaction and consultation envisioned for the new Public Health Law Association.

We are confident that the remarkable leadership that propels the public health law initiative, domestically and internationally, will take action on these two fronts and we look forward to reporting on major advances in public health's legal preparedness in next year's Journal issue on public health law and ethics.

\section{Referencis}

1. Selected legal resources related to the SARS epidemic and to the monkeypox outbreak are available at <http://www.cdc.gov/ncidod/sars/factsheetlegal.htm> and <http://www.phppo.cdc.gov/od/phlp/phlegalresponse. asp>, respectively (last visited October 28,2003 ).

2. Information about the draft model state emergency health powers act and related state activity is available at <http://www.publichealthlaw. net/Resources/Model laws.htm> (last visited October 28, 2003).

3. Information about the Framework Convention for Tobacco Control is available at <http://www.who.int/gb/ $\mathrm{fctc} />$ (last visited October 28, 2003).

4. Information about the Turning Point model act is available at <http://turningpointprogram.org/Pages/ MSPHAfinal.pdf> (last visited November 3, 2003).

5. A factsheet on the Forensic Epidemiology course and a contact for additional information, including technical assistance in delivering the course are available at <http:// www.phppo.cdc.gov/od/phlp/> (last visited October 28, 2003).

6. Information on the Public Health Law Association is posted at <http://www.tumingpointprogram.org/phlaw/> (last visited October 28, 2003).

7. The CDC Public Health Law Program website includes information on eight of the investigator-initiated, peer-reviewed public health law research projects it supports: <http://www.phppo.cdc.gov/od/phlp/ Research.asp $>$ (last visited October 28, 2003). 